\title{
ERIN: A practical tool for assessing work-related musculoskeletal disorders
}

\author{
Yordán Rodríguez*, Silvio Viña and Ricardo Montero \\ Faculty of Industrial Engineering, José A. Echeverría Polytechnic Institute, Havana, Cuba
}

\begin{abstract}
.
BACKGROUND: The number of work-related musculoskeletal disorders (WMSDs) has been increasing in industrially developing countries. Fortunately, it is possible to prevent these injuries through ergonomic assessment and job redesign. OBJECTIVE: This paper presents a practical tool for non-experts in assessing exposure to risk factors for WMSDs.

METHODS: Evaluación del Riesgo Individual (Individual Risk Assessment) (ERIN) is based on available ergonomic tools, epidemiological evidence and the joint International Ergonomics Association-World Health Organization project for developing WMSD risk management in developing countries.

RESULTS: ERIN focuses primarily on physical workplace factors but also includes the workers' assessment. A scoring system has been proposed to indicate the level of intervention required to reduce the risk of injury. Preliminary tests show that ERIN is easy and quick to use, but further work is needed to establish its reliability and validity. A worksheet has also been designed for increasing the usability of the tool.

CONCLUSIONS: The use of ERIN can contribute to the prevention of WMSDs in Cuba and other developing countries.
\end{abstract}

Keywords: Exposure assessment, work-related musculoskeletal disorders, observation method, ergonomic tool, posture

\section{Introduction}

It is now generally acknowledged in industrially advanced countries that musculoskeletal disorders adversely affect employees in most industries and occupations, and these injuries impose heavy costs on employers and society [1,2]. These injuries - which include disorders of the back, trunk, upper extremities, neck, and lower extremities - are one of the ten leading work-related illnesses and injuries in the United States [1]. Currently, these disorders have become one of the main focuses in the area of occupational disease prevention [3]. According to the European Agency for Safety and Health at Work, occupational musculoskeletal disorders are one of the major health issues in European workplaces [2]. About $24.7 \%$ of European workers consider that their work adversely affects their health in the form of backache. The situation is quite similar for muscular pains in the shoulders, neck, and/or upper/lower limbs, which are reported by about $22.8 \%$ of the workers [2].

In Cuba, WMSDs are not recognized in law as an occupational illness, nor are statistics kept on them. However, in studies carried out by the National Institute of Workers' Health (INSAT), WMSDs accounted for the second highest rate of total permanent disability in the Cuban work force in 2005, with 180 cases for every 10,000 workers - exceeded only by vascular-brain diseases, which had 186.9 cases

\footnotetext{
${ }^{*}$ Corresponding author: Yordán Rodríguez, Faculty of Industrial Engineering, José A. Echeverría Polytechnic Institute, Calle 114, no. 11901 e/ Ciclo Vía y Rotonda, CUJAE, Marianao, Havana 19390, Cuba. E-mail: ergcuba@gmail.com.
} 
for every 10,000 workers $[4,5]$. According to two other studies, WMSDs are one of the most prevalent work-related diseases in Cuba [6,7].

In Cuba, there are around 600 fully equipped physiotherapy centers [8], whose patients include those suffering from WMSDs. Most efforts in this field are reactive rather than preventive. There is a need to promote the prevention of WMSDs, in which the development of a tool for assessing risks at a workplace is a very important step, as is recognized by several authors $[9,10]$.

Even though the methods used for quantitative and qualitative assessment of work conditions and outcomes have been refined [11], limitations have been identified [9,12,13]. A review made recently by Takala et al. [13], classified 30 methods by potential users. According to this review, only two methods can definitely be used by workers and supervisors; six others are possibilities.

One easily used tool is needed in order to generalize the assessment of exposure to risk of WMSDs. In developing countries, such as Cuba, the potential users of the tool have little knowledge about WMSDs. As a result, they have little training in using tools for assessing their exposure to risk of WMSDs. Therefore, the development of a new tool that considers the objectives, needs, and limitations of these potential users in developing countries would be a valuable contribution to preventing WMSDs.

Observational methods of posture analysis have been considered a practical and reasonably reliable tool in musculoskeletal epidemiological research $[9,13,14]$. ERIN, which is an observational method, is based on such tools for assessing WMSDs at workplaces as Rapid Upper Limb Assessment (RULA), Rapid Entire Body Assessment (REBA), Strain Index (SI), and Quick Exposure Check (QEC) and seeks to overcome some of their limitations.

In RULA, the movement of the body parts has little impact on the final score, and time of exposure is not considered. The method is designed to be used mainly for sedentary tasks. ERIN includes the movements of the body parts, whose evaluation has great impact on the final score. Time exposure is also considered.

In QEC, the speed of work is not considered. Two worksheets are needed to score this method. Lastly, this method offers only a total score for each body part, which makes it difficult to assess the global risk of exposure. ERIN considers the speed of work and gives a global risk assessment. The RULA and QEC procedures are simple, but ERIN is even more so. Appendix A shows the ERIN worksheet.

This paper describes the development of ERIN, which was designed for use by non-experts with minimal training and few resources, to enable them to carry out large-scale assessments of individuals exposed to WMSD risk factors in static and dynamic tasks. The assessors can measure the effects of interventions aimed at reducing the global WMSD risk. The use of ERIN can contribute to the management and prevention of WMSDs in Cuba and other developing countries. The development of this observational tool follows the guidelines of the International Ergonomics Association (IEA) and World Health Organization (WHO) initiative for developing toolkits which non-experts can use at the workplace level to assess the risk of WMSD injuries.

\section{Development of ERIN}

ERIN has been developed taking into account experiences in field studies using such ergonomic tools as RULA, REBA, SI, QEC, the Occupational Repetitive Actions (OCRA) checklist, and the Ovako Working Posture Analyzing System (OWAS) [15-18]. It has also incorporated results from studies concerning work-related musculoskeletal disorders and risk factors, current methods for assessing exposure to WMSDs, feedback from industrial engineering students who have used ERIN in their projects and theses, and Cuban occupational safety and health practitioners.

The literature [10,19-23] shows that such tools should be 
- simple, easy, and quick to use;

- applicable to a variety of work situations;

- scientifically based; and

- comprehensive.

Moreover, they should

- involve workers,

- have scores to measure the levels of exposure,

- have instructions on how to use the tool and/or carry out assessments,

- not require many resources,

- take psychosocial aspects into consideration, and

- be easy to learn.

Finally, the recording equipment should not interfere with the worker's work and should be valid and reliable.

ERIN was developed taking the above considerations into account and gathering opinions from ergonomists, experts in occupational health and safety, industrial engineers, and specialists in human resources.

The proposed method involves the measurement or assessment of the following seven variables: posture and frequency of movement of the trunk, shoulder/arm, hand/wrist, and neck; the rhythm resulting from the interaction of work speed and the duration of each task; intensity of effort (which includes both the intensity and frequency of the perceived effort); and the worker's assessment of the stress required in carrying out the task.

The ERIN worksheet is shown in Appendix A. The representation of each variable follows four criteria:

1. In order to assess the postural load, ERIN uses a predefined posture categorization system similar to RULA [24]. This system of scoring each body part posture provides a sequence of numbers which is logical and easy to remember.

2. In order to make posture identification easier, ERIN combines images and descriptive words [12].

3 . The posture categorization system is divided into a few levels to increase the reliability and validity $[25,26]$.

4. The categorization of movement of body parts takes into account the risk model for health associated with posture and movement [27].

\subsection{Description of variables}

Trunk posture and frequency of movement:

- Trunk posture

Trunk posture is based on RULA, with some modifications [24].

- Frequency of trunk movement

Trunk movement is divided into four ranges based on the findings reported by Parnianpour and ShiraziAdl [28], adding the static posture [27].

Shoulder/arm posture and frequency of movement:

- Shoulder/arm posture

Posture classification is based on RULA [24] and LUBA [29]. 
- Frequency of shoulder/arm movement

Shoulder/arm movement is divided into four ranges, based on QEC [20], adding static posture [27]. Hand/wrist posture and frequency of movement:

- Hand/wrist posture

Posture classification is based on REBA [30] and the remarks made by Ketola et al. [31].

- Frequency of wrist/hand movement

ERIN uses the same approach as the QEC method in order to assess repetitive wrist/hand movements [20].

Neck posture and frequency of movement:

- Neck posture

Several authors have analyzed neck posture [14,20,24,29,30,32,33]. Posture classification is based on the results reported by Colombini et al. [34] and Bonneys and Corlett [35].

- Frequency of neck movement

Neck movement is divided into three frequency ranges, based on QEC [20] and on the risk model for health associated with posture and movement [27].

\section{Rhythm of work (work activity):}

This variable is the interaction of speed of work [36] and task duration per day, categorized into four durations and five speeds.

\section{Intensity of effort:}

This variable combines the intensity of the worker's exertion - which, as defined by Moore and Garg, is an estimate of the force requirements of a task, reflecting the magnitude of muscular effort required to perform the task one time [36] - and frequency of effort, which is divided into three categories [28]. The intensity of effort can be evaluated using the criteria of the observer (the efficacy of vicarious perception by non-experts has been reported by Drury et al. [37]) and by asking the observed worker, encouraging worker participation.

\section{Worker's assessment:}

Stress due to work and workplace conditions has an important influence on musculoskeletal health [38, 39]. Many of the effects of these psychosocial factors occur via stress-related processes, which can have a direct effect on biochemical and physiological responses [40]. In ERIN, workers are asked about their perception of how stressful they find their work to be, using the QEC approach [20], plus an additional, "stressful", category of exposure.

\subsection{Steps for determining the ERIN score}

Using the worksheet shown in Appendix A:

(1) Observe the task.

(2) Score the risk values per variable.

(3) Add all the risk values to obtain the global risk.

(4) Determine the corresponding risk level, based on the global risk. 
Table 1

Weight variables

\begin{tabular}{lc}
\hline Variables & Weight range \\
\hline Trunk & $1-9$ \\
Shoulder/arm & $1-9$ \\
Wrist/hand & $1-6$ \\
Neck & $1-7$ \\
Rhythm of work & $1-7$ \\
Intensity of effort & $1-9$ \\
Worker's assessment & $1-5$ \\
\hline
\end{tabular}

The following aspects have also been taken into account:

For an observer, the number of body joints and number of posture categories that can be observed simultaneously are limited when real-time posture categorization decisions are required [14]. Therefore, when working postures are variable in time, the observer should select the worst posture for each body part assessed. This facilitates observation for non-experts.

As the strength required on the job increases, the injury incidence also increases [41]. However, the level of strength required that may be considered a neutral risk is unclear [41]. If there are several types of effort, it is recommended that the greatest intensity of effort should be selected, because the average level of force required can hide the presence of peaks [42], and non-experts may find it difficult to estimate that average.

Frequency of movement is determined by the number of times the body part moves and is not related to the number of times the worst posture occurs.

\subsection{Scoring system}

Most scoring systems used in existing methods have been based on estimates [12]. Sufficient data for creating an accurate, parametric general model that combines all the risk factors, particularly when the goal is to fix the "specific weight" of each factor in determining the overall exposure level is still lacking $[12,42]$, but a need to have even partially empirical models for a synthetic assessment of overall exposure to the risk factors has been stated [42].

ERIN's scoring system was designed to provide non-experts with a tool for carrying out interventions based on "before and after" comparisons of global risk levels. This scoring system will need further development and refinement based on future epidemiological research. For example, after several years of use, the scoring system in the OCRA method has been updated, based on clinical data [43].

The ERIN scoring system reflects the global risk level as determined by seven variables, each of which has been assigned a weight, expressed as the maximum value for each variable (Table 1). This weight assignment is based on the author's experience and on the sensitivity analyses of RULA, REBA, and SI [44]. This study was designed to detect critical variables for the tools evaluated [44]. A variable is considered sensitive when change in it produces a subsequent change in the outcome, and critical when change in it produces a subsequent change in the estimate of the hazard level. Though a critical variable must be sensitive, a sensitive variable is not necessarily critical. According to the criteria in this study, the upper arm is the most critical variable in the RULA assessment, followed by the neck, trunk, and legs. The trunk is the most critical variable in the REBA assessment, followed by the upper arm, legs, neck, and wrist. The critical variables in SI, arranged from most to least critical, were (1) intensity of the exertion, (2) speed of work, (3) hand/wrist posture, (4) duration of the exertion and efforts per minute, and (5) duration per day. Obviously, the most critical variables require more attention and care when being assessed [44]. 


\subsection{Global risk}

The global risk is obtained by adding the values for all of the seven variables assessed in ERIN. The model used for calculating the global risk makes it possible to easily identify the influence of each factor and which to address in order to reduce the global risk.

When the global risk is between 7 and 14 - that is, at a low level - no changes are required. To establish the upper limit of this risk level, the seven variables evaluated in ERIN had a maximum value of two points, which implies a low level of exposure. Moreover, to be in this low risk level, none of the variables may reach the maximum score of nine assigned to the ERIN variables (Table 1), since, even if the other variables had low scores - even the minimum of 1 - the sum of the seven variables could be greater than 14 - and, therefore, would place the total in the next level.

When the global risk is between 15 and 23 - that is, at a medium level - further investigation is needed and changes may be required. Initially, a value of 21 was established as the upper limit of this risk level, since it was thought that the scores of the seven variables would be around three points each. Later, the range of values for this level was enlarged to 23, because a group of real situations that were considered to be of low risk was analyzed and, because of the narrowness of the range of values at this level, they fell into the high-risk level.

When the global risk is between 24 and 35 - that is, at a high level - investigation and changes are required soon. To establish the upper limit of this risk level, it was considered that each of the seven variables assessed with ERIN should have a value of around five points. For this risk level, some of the variables may have values up to and including maximum scores, clearly reflecting the fact that several factors at the workstation may adversely affect the worker's health and measures should be taken to reduce the level of exposure to risk factors.

When the global risk is more than 36 - that is, at a very high level - investigation and changes are required immediately. For a task to be classified at this level, most of the variables have values up to and including maximum scores. This means that the worker has to adopt awkward postures, carry out frequent movements or maintain static postures, and make great efforts over a long time.

While ERIN was being developed, the scoring system was assessed and improved by using the method continuously in field studies. Even though no formal studies were made, it was found that the tasks that ERIN classified as high risk of exposure were generally the ones that the workers said required greater physical work to carry out. The opposite was true of tasks that scored low risk of exposure using ERIN.

\subsection{The ergonomic intervention process using ERIN}

ERIN has been used in different kinds of workplaces [17,45]. In general, the practitioners have followed the ergonomic intervention process that is described below in using this tool:

\subsubsection{Selection of workplaces and tasks to be assessed}

Though ERIN was designed to make large - scale assessments in workplaces, an order of priorities should be established. In selecting the workplaces to be evaluated, the WMSD statistics; musculoskeletal symptoms; opinions of the workers, area chiefs, and supervisors; and the impact of the workstation in the production system should be considered, among other aspects. The greater the experience and knowledge of the person conducting the study, the more likely he will make a correct selection. 


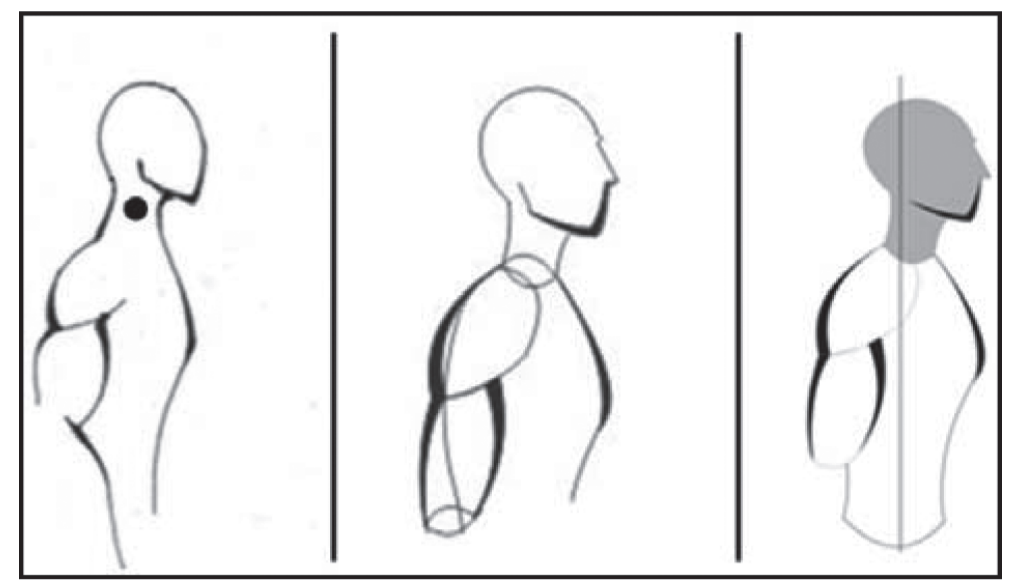

Fig. 1. Evolution of a mannequin in the ERIN worksheet.

\subsubsection{Assessment using the ERIN worksheet (explained in Subsection 2.2)}

In this step the workplaces and tasks of greatest risk, which need to be changed to reduce exposure to WMSD risk factors, are identified. In this case, ERIN has been used to establish priorities. If the evaluation brings out risk factors not considered in ERIN (such as vibration and awkward posture of the lower extremities), they should be recorded for later analysis.

\subsubsection{Proposal of solutions to reduce ERIN scores}

The proposals (e.g. engineering and administrative) that are made on the basis of the ERIN evaluation should reduce those scores - at least for the variables with the highest scores. Proposals should be accompanied by "before" and "after" ERIN scores. Even if changes in the scores for the variables do not reduce the risk level, a movement is created that is focused on improving the working conditions from the ergonomic point of view. It is very important for the workers to participate in making the proposals and that these proposals be backed up by a cost-benefit analysis.

\subsubsection{Implementation of solutions}

This has been the most complicated step in the intervention process, because solutions are often not implemented for lack of resources or because the need for change has not been sufficiently explained, since the personnel using the ERIN method often have not received the training required to explain the proposals in business terms. Fortunately, the proposals often involve a negligible - or no - cost, which has helped their implementation.

\subsubsection{Re-assessment using ERIN}

Once the task has been changed, another ERIN evaluation should be conducted. This makes it possible to see if the measures that have been taken are really effective in terms of reducing the worker's exposure to WMSD risk factors.

\subsection{Findings and recommendations resulting from ERIN applications in field studies}

- Hand/wrist postures were the most difficult to observe correctly. This situation has been reported by other researchers $[20,46,47]$. 
- It was difficult for observers to classify the frequency of movements of the body part assessed and speed of work in real time.

- To facilitate the posture and frequency-of-movement assessments, it is recommended that novice observers using ERIN videotape the tasks to be assessed, since new video techniques make it easy to use a slow-motion camera and to freeze images. In spite of the advantages provided by videotaping, this technique should be used with care, to avoid problems with the quality of the videos [48].

- Observers found it difficult to decide if the effort was "light" or "somewhat hard" - a situation that has been reported by Moore and Garg [36]. In order for this difficulty not to affect the global risk, the same score was assigned to both categories.

- Although ERIN is easy to use and its results are simple to determine, a training time of approximately three hours is recommended.

- It takes less than ten minutes to assess a task using ERIN [49].

- It is difficult to assess posture when the work posture is border-line between two sectors. In this situation, it is recommended that the higher of the two scores be taken. This approach ensures that all risks are included.

- Observers reported that the mannequins used at first to represent the posture categories did not facilitate the posture assessment. Therefore, efforts were made to develop new mannequins (Fig. 1).

- Observers considered the ERIN worksheet to be very user-friendly and useful for showing managers the need for changes in the tasks evaluated.

\subsection{Reliability and validity studies of ERIN}

Reliability is a measure of the capability to replicate measurements of the same object of study, while validity refers to the ability of a tool to accurately measure what is intended [47,50,51].

Reliability is usually divided into inter-observer and intra-observer reliability. Inter-observer reliability refers to the ability of a tool to produce the same measurement regardless of the observer $[47,50]$. Intra-observer reliability is the ability of a tool to be stable over time or its ability to replicate previous measurements by the same observer [50,51], so it requires a re-test.

The validity of an exposure assessment tool has several dimensions [13,52]. Content validity refers to the completeness of the assessment [53]; concurrent validity refers to how well the results of the method correspond with those obtained using other, recognized methods [13]; and predictive validity refers to the ability of the method to predict risks - which can be studied by analyzing the associations between exposures obtained by the method and the outcomes of interest, such as musculoskeletal disorders [13, 54]. Another kind of validity is face validity - defined as how the method appears to measure what it is intended to measure [13].

At this time there are no published studies concerning the reliability and validity of ERIN. Takala et al. [13] have reported the same with respect to many other methods. Nevertheless, due to the importance of reliability and validity tests for an exposure assessment method, trials have been outlined for assessing these characteristics.

\subsubsection{Reliability trials}

To assess inter-observer reliability using ERIN, a sample of at least ten non-expert observers should receive training in the use of ERIN. These observers should evaluate at least seven dynamic and static tasks using the ERIN worksheet. These evaluations should be conducted on site [46] or be based on films [20]. The scores that the observers give for the variables measured for each task using ERIN should be analyzed using the statistical methods recommended for each kind of variable $[26,46,47]$. 


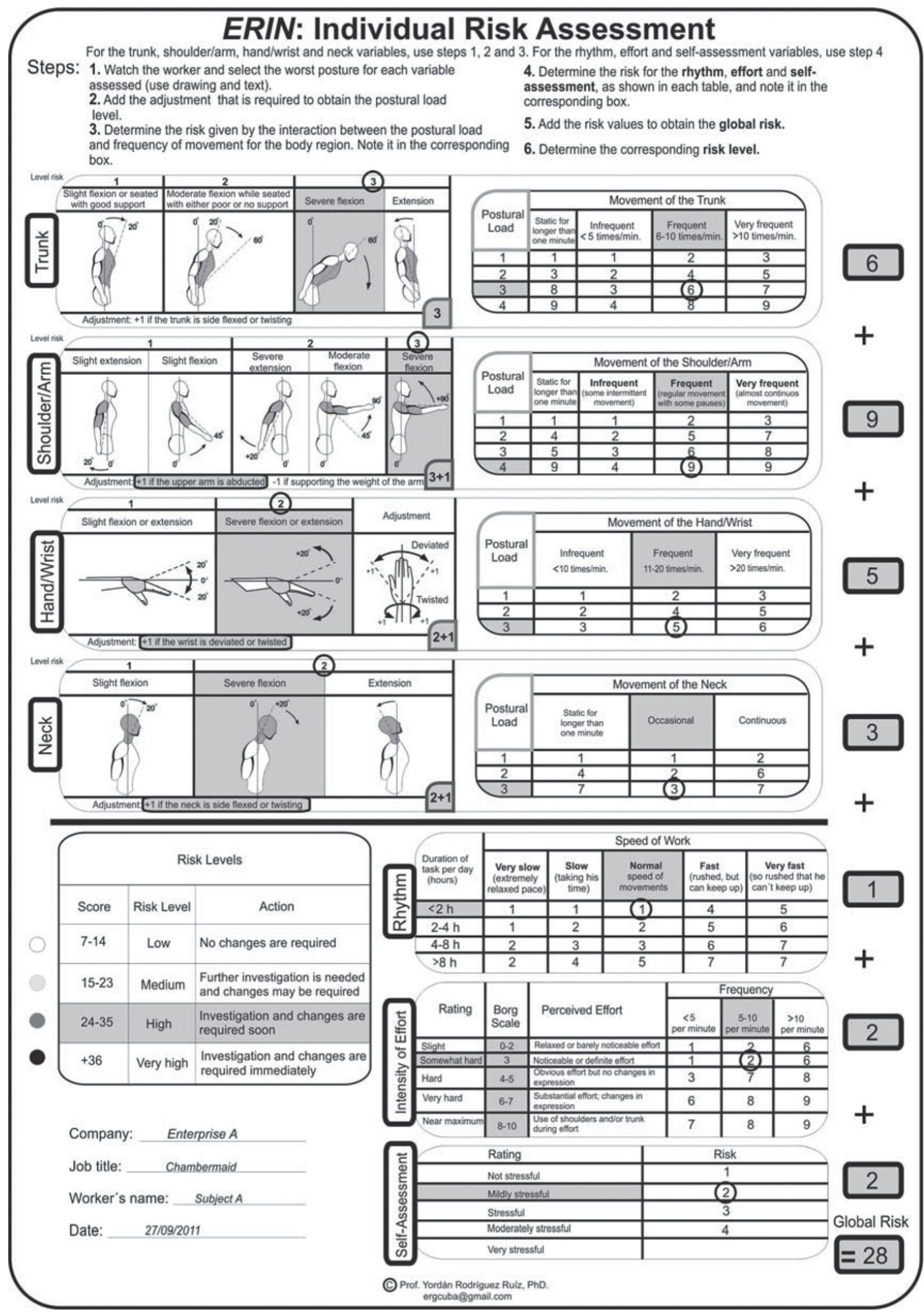

Fig. 2. Completed ERIN worksheet regarding a chambermaid making up a hotel bed. 


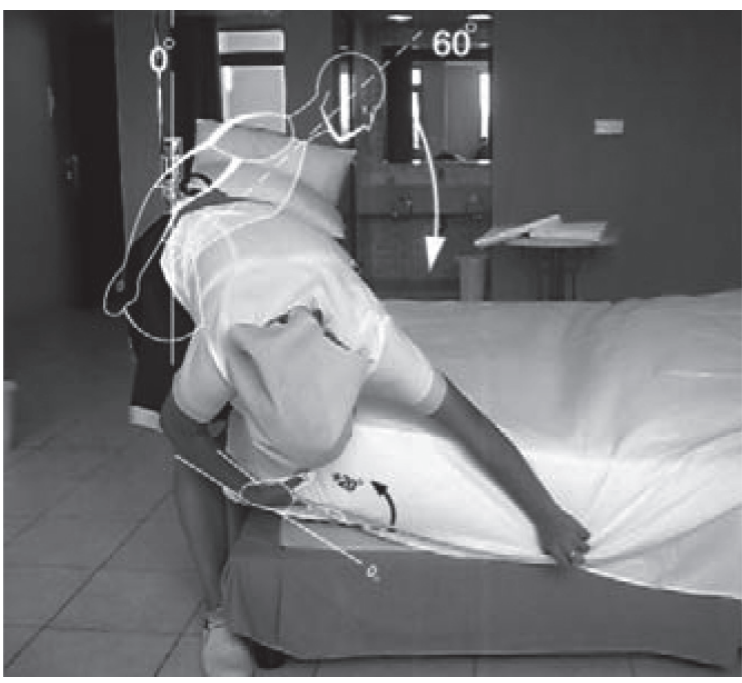

Fig. 3. Worst trunk and wrist posture.

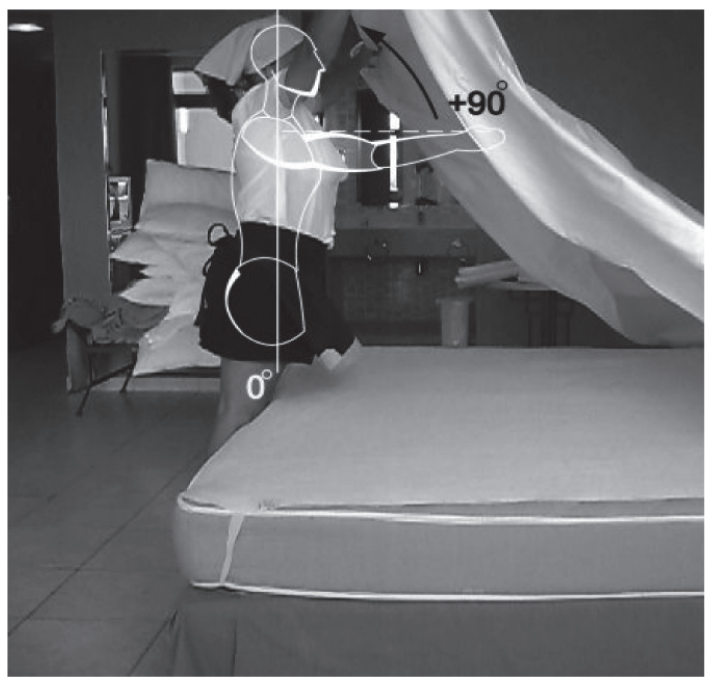

Fig. 4. Worst shoulder/arm posture.

Intra-observer reliability should be evaluated by means of films, to guarantee that the same tasks are evaluated in the test and re-test $[20,51]$. At least three weeks should separate the two [20,51,55]. Intraobserver reliability should be evaluated by comparing the scores given for the variables in each task by each observer in the test and re-test $[20,51,55]$.

The variety of tasks should be kept in mind when selecting them, and good quality should be guaranteed in the filming [20,26,51]. In order to best re-create the way most observers conduct their evaluations, the observers should not compare opinions during the evaluation, nor should they stop the video of the tasks they are evaluating.

\subsubsection{Validity trials}

One way to assess the criterion validity of ERIN is to evaluate the concurrent validity. In doing this, it is necessary to establish which criterion is most valid for comparison, which can be done by having a group of experts assess each of these selected tasks [13,20]. The evaluations made by the observers using ERIN should be compared with those made by this group of experts [13]. The experts should be allowed to consult among themselves, solving discrepancies by consensus; they should also be allowed to stop the video to analyze postures and use a slow-motion camera to determine movement frequency.

Another commonly-used way to assess the concurrent validity of a method is to compare the results obtained by using this method with those obtained through other methods [13]. For example, ERIN's results can be compared with those obtained by using QEC, REBA, and RULA in assessing the same task.

With regard to predictive validity, even though ERIN does not provide an absolute statement of the exposure to WMSD risk, its use makes it possible to rank exposure levels, mainly by combining the various factors in different work situations, and, thus, to assign priorities for actions and interventions. In a small sample of five workstations in an aluminum auto-parts company, a relationship was found between the global risk as measured by ERIN and the total WMSDs registered over six years at those workstations [17].

Even so, further work is needed to establish the validity of the method. To date, ERIN has been applied in different workplaces in various developing countries, including Cuba, Colombia, Mexico and 


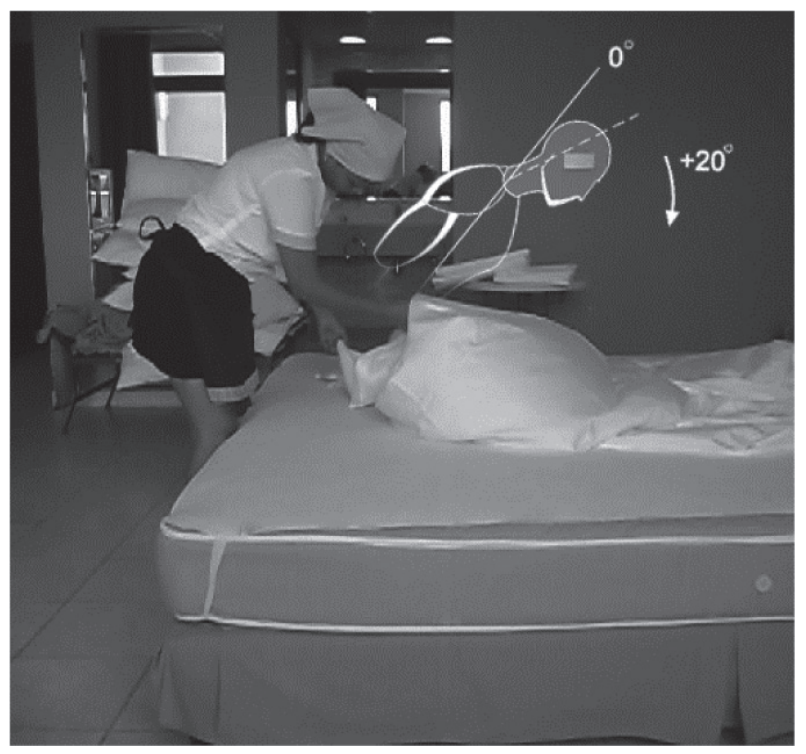

Fig. 5. Worst neck posture.

Peru. Several ERIN courses have been given in these countries, and the practitioners, workers, and other interested parties who have used it have found it to be a useful tool. This establishes good face validity for ERIN. Moreover, in situations in which practical ergonomic problems have to be solved (such as in developing countries), simplicity, utility, and the face validity of the method are more important than expressing results in exact numerical figures $[12,13,56]$.

Finally, it should be mentioned that various statistical methods (such as kappa statistic, percentage of agreement between raters, and intraclass correlation coefficient $[20,26,46,47,51,54])$ have been used in reliability and validity studies. The strengths and limitations of these statistical methods should be studied, since there is little consensus about which statistical methods are most suitable for making each analysis $[26,47,51]$.

\section{Example of ERIN application}

The following example illustrates the use of ERIN at the workplace level. Here, a chambermaid is making a bed in a hotel. Figure 2 shows the completed ERIN worksheet.

As explained above, the observer must decide which is the worst posture adopted for each body part. Figure 3 shows that, even though the trunk is not side flexed or twisted, it is flexed more than $60^{\circ}$ (3) and the right wrist is flexed more than $20^{\circ}$ and deviated $(2+1)$. In this case, the worst posture of trunk and wrist occur simultaneously. The movement of the trunk is frequent (6-10 times/min.), as is the movement of the wrist (11-20 times/min.).

Figure 4 shows that the shoulder/arm is flexed more than $90^{\circ}$ and abducted $(3+1)$. The movement of the arm is frequent (regular movement with some pauses). Figure 5 shows that the neck is flexed more than $20^{\circ}$ and side flexed $(2+1)$. Neck movement is occasional.

The chambermaid spends less than two hours in this task during the working day and performs it at a normal speed of work. The intensity of effort is considered "somewhat hard", with a frequency of five to ten per minute, and the worker assesses the task as mildly stressful. 
The global risk score is 28 , corresponding to a high risk level, indicating that investigation and changes are required soon.

\section{Conclusions}

ERIN was developed in line with the IEA and WHO's initiative for developing toolkits which nonexperts can use at the workplace level to assess the risk of WMSDs. The proposed tool can be used by non-experts with minimal training in evaluating dynamic and static tasks, without the need for any equipment. ERIN can be used as an instrument to determine in which cases interventions should be instituted to reduce the worker's exposure to WMSD factors and to measure the effects of those measures.

Although experience to date shows that ERIN will be a valuable tool for the prevention of WMSDs, further studies are needed to establish the reliability and validity of the tool.

\section{Acknowledgements}

Our thanks to Mary Todd for her assistance in translation and to the anonymous reviewers for their valuable comments on a previous manuscript.

\section{References}

[1] NIOSH. Musculoskeletal Disorders and Workplace Factors: A Critical Review of Epidemiologic Evidence for WorkRelated Musculoskeletal Disorders of the Neck, Upper Extremity, and Low Back. In: Department of Health and Human Services US, Public Health Service, Centers for Disease Control and Prevention, National Institute for Occupational Safety and Health, editor. Cincinnati: DHHS (NIOSH), 1997, pp. 97-147.

[2] European Agency for Safety and Health at Work. OSH in figures: Work-related musculoskeletal disorders in the EU Facts and figures. Luxembourg: Publications Office of the European Union, 2010.

[3] Colombini D, Occhipinti E. Preventing upper limb work-related musculoskeletal disorders (UL-WMSDS): New approaches in job (re)design and current trends in standardization. Applied Ergonomics. 2006; 37: 441-50.

[4] Torres Y, Rodríguez Y, Viña S. Preventing work-related musculoskeletal disorders within Cuba, an industrially developing country. WORK: A Journal of Prevention, Assessment and Rehabilitation. 2011; 38(3): 301-6.

[5] Linares TME, Díaz W. Evaluación epidemiológica de la invalidez total. Cuba 2005. Revista Cubana de Salud y Trabajo. 2007; 8(1): 15-21.

[6] Serrano W, Caballero EL, Valero H. Trastornos musculoesqueléticos relacionados con las condiciones de trabajo de estibadores y operadores de equipos montacargas en el puerto de La Habana. Revista Cubana de Salud y Trabajo. 2005; 6(1): 19-26.

[7] González J, Valero H, Caballero EL. Estudio de riesgos de lesiones músculo esqueléticas en las fábricas de pinturas 'Vitral' y de helados 'Coppelia'. Revista Cubana de Salud y Trabajo. 2004; 5(2): 31-40.

[8] Castro F. Un ejemplo de conducta comunista. Granma. 2008.

[9] David G. Ergonomic methods for assessing exposure to risk factors for work-related musculoskeletal disorders. Occup Med (Lond). 2005; 55(3): 190-9.

[10] Haslegrave CM, Corlett EN. Evaluating work conditions and risk of injury-techniques for field surveys. In: Wilson JR, Corlett EN, editors. Evaluation of Human Work A practical ergonomics methodology. London: Taylor and Francis, 1995, pp. 892-920.

[11] Kilbom Å, Prevention of work-related musculoskeletal disorders in the workplace. Editorial/International Journal of lndustrial Ergonomics. 1998; 21(Special issue): 1-3.

[12] Li G, Buckle P. Current techniques for assessing physical exposure to work-related musculoskeletal risks, with emphasis on posture-based methods. Ergonomics. 1999; 42(5): 674-95.

[13] Takala E-P, Pehkonen I, Forsman M, Hansson G-A, Mathiassen S, Neumann W, et al. Systematic evaluation of observational methods assessing biomechanical exposures at work. Scand J Work Environ Health 2010; 36(1): 3-24. 
[14] Bao S, Howard N, Spielholz P, Silverstein B. Two posture analysis approaches and their application in a modified Rapid Upper Limb Assessment evaluation. Ergonomics. 2007; 50(12): 2118-36.

[15] Torres Y, Rodríguez Y. Ergonomic intervention for reducing the exposure to musculoskeletal disorders risk factors in pharmaceutical production centre. Ergonomics SA. 2012; 24(2): 58-75.

[16] Torres Y, Rodríguez Y, Viña S, editors. Cuban experience in modeling ergonomic redesigns of work places in pharmaceutical industry. Proceedings of CybErg 2008: Fifth International Cyberspace Conference on Ergonomics, 2008, Malaysia.

[17] Rodríguez Y, Guevara C. Assessment of workstations using ERIN and RULA ergonomic tools. Revista de Ingeniería Industrial. 2011; 32(1).

[18] Viña S, Rodríguez A, Delgado S, Serradet A, editors. Diagnosis and design of workplaces at ARCA factory. Proceedings of CybErg 2005: The Fourth International Cyberspace Conference on Ergonomics; 2005; Johannesburg: International Ergonomics Association Press.

[19] Aarås A, Stranden E. Measurement of postural angles during work. Ergonomics. 1988; 31(6): 935-44.

[20] David G, Woods V, Li G, Buckle P. The development of the Quick Exposure Check (QEC) for assessing exposure to risk factors for work-related musculoskeletal disorders. Applied Ergonomics. 2008; 39(1): 57-69.

[21] Sinclair MA. Subjective assessment. In: Wilson JR, Corlett EN, editors. Evaluation of Human Work A practical ergonomics methodology. London: Taylor and Francis, 1995, pp. 69-100.

[22] Wilson JR. A framework and a context for ergonomics methodology. In: Wilson JR, Corlett EN, editors. Evaluation of Human Work A practical ergonomics methodology. London: Taylor and Francis, 1995, pp. 1-39.

[23] Karhu O, Kansi P, Kuorinka I. Correcting working postures in industry: a practical method for analysis. Applied Ergonomics. 1977; 8(4): 199-201.

[24] McAtamney L, Corlett EN. RULA: a survey method for the investigation of work-related upper limb disorders. Applied Ergonomics. 1993; 24(2): 91-9.

[25] Kilbom $\AA$, Assessment of physical exposure in relation to work-related musculoskeletal disorders - what information can be obtained from systematic observations? Scand J Work Environ Health. 1994; 20(Special issue):30-45.

[26] Bao S, Howard N, Spielholz P, Silverstein B, Polissar N. Interrater Reliability of Posture Observations. Human Factors: The Journal of the Human Factors and of Ergonomics Society. 2009; 51(3): 292-309.

[27] UNE-EN 1005-4. Seguridad de las máquinas. Comportamiento físico del ser humano. Parte 4: Evaluación de las posturas y movimientos de trabajo en relación con las máquinas, 2005, p. 11.

[28] Parnianpour M, Shirazi-Adl A. Quantitative Assessment of Trunk Performance. In: Karwowski W, Marras WS, editors. The Occupational Ergonomics Handbook. Boca Raton, Florida 1999, pp. 985-1006.

[29] Kee D, Karwowski W. LUBA: an assessment technique for postural loading on the upper body based on joint motion. Applied Ergonomics. 2001; 32(4): 357.

[30] Hignett S, McAtamney L. Rapid Entire Body Assessment (REBA). Applied Ergonomics. 2000; 31: 201-5.

[31] Ketola R, Toivonen R, Viikari-Juntura E. Interobserver repeatability and validity of an observation method to assess physical loads imposed on the upper extremities. Ergonomics. 2001; 44(2): 119-31.

[32] Kee D, Karwowski W. Ranking systems for evaluation of joint and joint motion stressfulness based on perceived discomforts. Applied Ergonomics. 2003; 34(2): 167.

[33] Seth V, Weston RL, Freivalds A. Development of a cumulative trauma disorder risk assessment model for the upper extremities. International Journal of Industrial Ergonomics. 1999; 23: 281-91.

[34] Colombini D, Occhipinti E, Frigo C, Pedotti A, Grieco A. Biomechanical, electromyographical and radiological study of seated postures. In: Corlett EN, Wilson JR, Manenica I, editors. Ergonomics of Working Postures. London: Taylor and Francis, 1985.

[35] Bonneys RA, Corlett EN. Head posture and loading of the cervical spine. Applied Ergonomics. 2002; $33(5)$ : 415.

[36] Moore JS, Garg A. The Strain Index: A Proposed Method to Analyze Jobs for Risk of Distal Upper Extremity Disorders. Amer Indus Hyg Assoc J. 1995; 56(5): 443-56.

[37] Drury CG, Atiles M, Chaitanya M, Lin J-F, Marin C, Nasarwanji M, et al. Vicarious perception of postural discomfort and exertion. Ergonomics. 2006; 49(14): 1470-85.

[38] Carayon P, Lim S-Y. Psychosocial Work Factors. In: Karwowski W, Marras WS, editors. The Occupational Ergonomics Handbook. Boca Raton, Florida, 1999, pp. 275-93.

[39] Devereux JJ, Vlachonikolis IG, Buckle PW. Epidemiological study to investigate potential interaction between physical and psychosocial factors at work that may increase the risk of symptoms of musculoskeletal disorder of the neck and upper limb. Occup Environ Med. 2002; 59(4): 269-77.

[40] ISO 11228-3. Ergonomics -Manual handling-. Part 3: Handling of low loads at high frequency 2007.

[41] Kumar S. Theories of musculoskeletal injury causation. Ergonomics. 2001; 50(1): 17-47.

[42] Colombini D, Occhipinti E, Delleman N, Fallentin N, Kilbom A, Grieco A. Exposure Assessment of Upper Limb Repetitive Movements: A Consensus Document. In: Karwowski W, editor. International Encyclopedia of Ergonomics and Human Factors: Taylor and Francis, 2001, pp. 55-72. 
[43] Occhipinti E, Colombini D. Updating reference values and predictive models of the OCRA method in the risk assessment of work-related musculoskeletal disorders of the upper limbs. Ergonomics. 2007; 50(11): 1727-39.

[44] Escobar CP. Sensitivity analysis of subjective ergonomic assessment tools: impact of input information accuracy on output (final scores) generation. [Master of Science]. Alabama: Auburn, 2006.

[45] Rodríguez Y, Pérez E. Ergonomics and simulation applied to the industry. Revista de Ingeniería Industrial. 2011; 32(1).

[46] Burt S, Punnett L. Evaluation of interrater reliability for posture observations in a field study. Applied Ergonomics. 1999; 30(2): 121-35.

[47] Stevens EM, Vos GA, Stephens J-P, Steven Moore J. Inter-Rater Reliability of the Strain Index. Journal of Occupational and Environmental Hygiene. 2004; 1(11): 745-51.

[48] Cochran DJ, Stentz TL, Stonecipher Bl, Hallbeck MS. Guide for Videotaping and Gathering Data on Jobs Analysis of Risks of Musculoskeletal Disorders. In: Karwoski W, Marras WS, editors. The Occupational Ergonomics Handbook. Boca Ratón Florida, 1999, pp. 511-24.

[49] Rodríguez Y. ERIN: método práctico para evaluar la exposición a factores de riesgo de desórdenes músculo-esqueléticos [PhD Dissertation]. Havana, Cuba: José A. Echeverría Polytechnic Institute, 2011.

[50] Fagarasanu M, Kumar S. Measurement instruments and data collection: A consideration of constructs and biases in ergonomics research. International Journal of Industrial Ergonomics. 2002; 30: 355-69.

[51] Stephens J-P, Vos GA, Stevens EM, Steven Moore J. Test-retest repeatability of the Strain Index. Applied Ergonomics. 2006; 37(3): 275-81.

[52] Leonard VK, Jacko JA, Soo Yi J, Sainfort F. Human Factors and Ergonomic Methods In: Salvendy G, editor. Handbook of Human Factors and Ergonomics. New Jersey: John Wiley and Sons, INC., 2006, pp. 292-321.

[53] Wells R. Integrated analysis of upper extremity disorders. In: Karwowski W, Marras WS, editors. The occupational ergonomics handbook. Boca Raton, Florida, 1999, pp. 775-94.

[54] Rucker N, Moore JS. Predictive Validity of the Strain Index in Manufacturing Facilities. Applied Occupational and Environmental Hygiene. 2002; 17(1): 63-73.

[55] Bruijn I, Engels JA, Gulden JWJ. A simple method to evaluate the reliability of OWAS observations. Applied Ergonomics. 1998; 29(4): 281-3.

[56] David G. Ergonomic methods for assessing exposure to risk factors for work-related musculoskeletal disorders. Occupational Medicine. 2005; 55(3): 190-9. 


\section{Appendix A. ERIN worksheet}

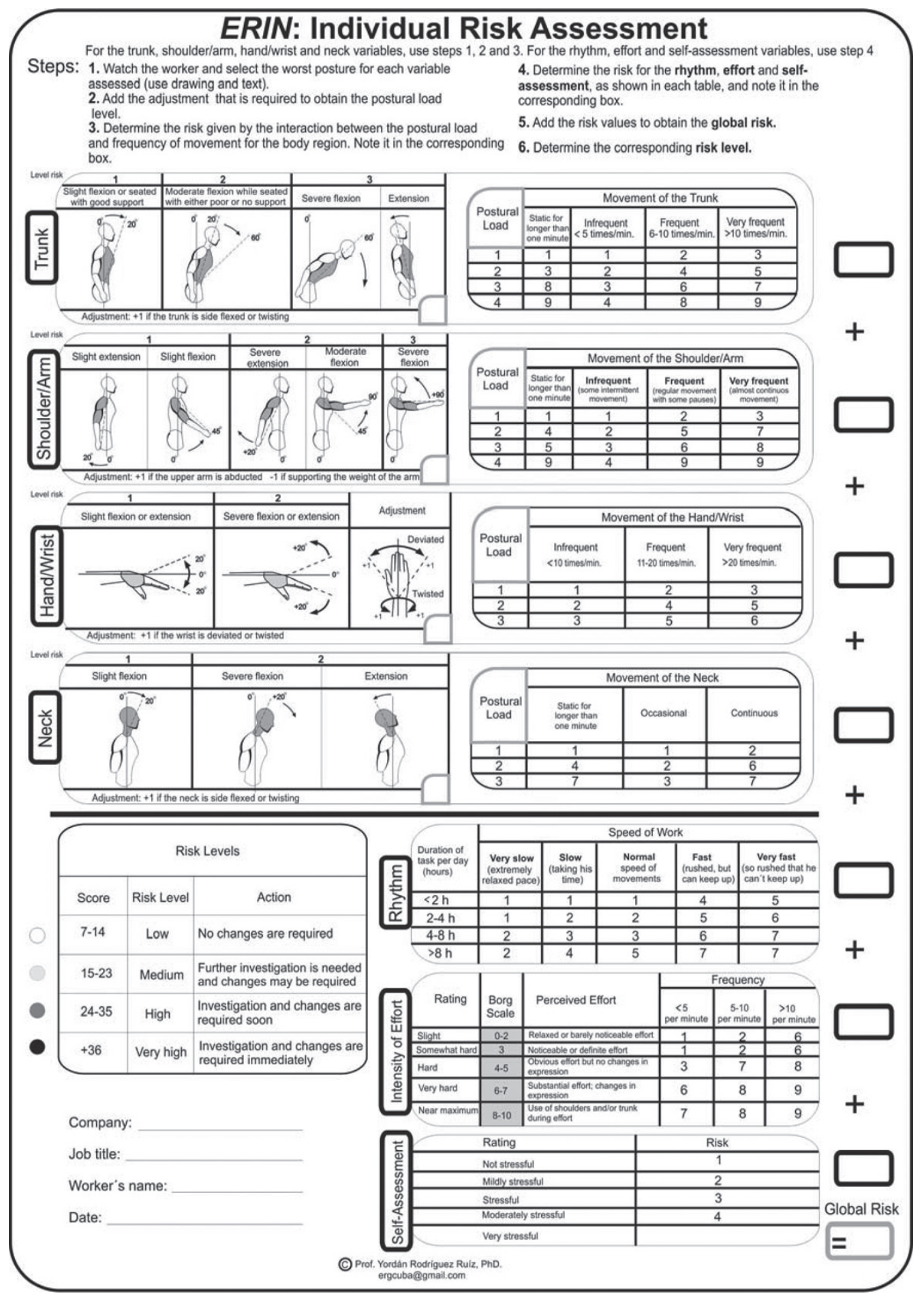

